\title{
CD44 Variant 9 Serves as a Poor Prognostic Marker in Early Gastric Cancer, But Not in Advanced Gastric Cancer
}

\section{Se-II Go, MD ${ }^{1}$ \\ Gyung Hyuck Ko, MD, PhD² \\ Won Sup Lee, MD, PhD'1 \\ Rock Bum Kim, MD, PhD ${ }^{3}$ \\ Jeong-Hee Lee, MD, PhD² \\ Sang-Ho Jeong, MD, $\mathrm{PhD}^{4}$ \\ Young-Joon Lee, MD, PhD ${ }^{4}$ \\ Soon Chan Hong, MD, $\mathrm{PhD}^{4}$ \\ Woo Song Ha, MD, PhD ${ }^{4}$}

\author{
${ }^{1}$ Department of Internal Medicine, \\ Institute of Health Sciences, \\ Gyeongsang National University \\ School of Medicine, Jinju, \\ ${ }^{2}$ Department of Pathology, \\ Institute of Health Sciences, \\ Gyeongsang National University \\ School of Medicine, Jinju, \\ ${ }^{3}$ Department of Preventive Medicine and \\ Environmental Health Center, \\ Dong-A University College of Medicine, \\ Busan, ${ }^{4}$ Department of Surgery, \\ Institute of Health Sciences, \\ Gyeongsang National University \\ School of Medicine, Jinju, Korea
}

Correspondence: Won Sup Lee, MD, PhD

Department of Internal Medicine,

Institute of Health Sciences and

Gyeongnam Regional Cancer Center,

Gyeongsang National University

School of Medicine, 79 Gangnam-ro,

Jinju 52727, Korea

Tel: 82-55-750-8733

Fax: 82-55-758-9122

E-mail:1wshmo@hanmail.net

Received August 12, 2014

Accepted January 2, 2015

Published Online March 17, 2015

*Se-Il Go and Gyung Hyuck Ko contributed equally to this work.

\section{Purpose}

The present study is to investigate the significance of CD44 variant 9 (CD44v9) expression as a biomarker in primary gastric cancer.

\section{Materials and Methods}

With various gastric tissues, we performed immunohistochemical staining for CD44v9.

\section{Results}

The positive expression rates for CD44v9 in tumor, including adenoma, early gastric cancer (EGC), and advanced gastric cancer (AGC), were higher than those in non-tumor tissues $(p=0.003)$. In addition, the higher expression for CD44v9 was observed as the tissue becomes malignant. In the analysis of 333 gastric cancer tissues, we found that positive expression rates for CD44v9 were higher in the intestinal type or well differentiated gastric cancer than in the diffuse type or poorly differentiated gastric cancer. Interestingly, the positive expression indicated poor prognosis in EGC (5-year survival rate [5-YSR] in stage I, 81.7\% vs. 95.2\%; $p=0.013$ ), but not in AGC (5-YSR in stage II, $66.9 \%$ vs. $62.2 \% ; p=0.821$; 5 -YSR in stage III, $34.5 \%$ vs. 32.0\%; $p=0.929)$. Moreover, strong positive expression (3+) showed a trend suggesting worse prognosis only in EGC, and it appeared to be associated with lymph node metastasis.

\section{Conclusion}

This study suggests that CD44v9 may be a good biomarker for prognosis prediction and for chemoprevention or biomarker-driven therapies only for EGC. 


\section{Introduction}

Gastric cancer is the fourth most prevalent cancer worldwide, with the highest prevalence in Korea [1]. However, the treatment outcome, although detection of early gastric cancer (EGC) has improved cure rates, is still unsatisfactory because some of the EGCs relapse with loco-regional or distant metastasis even after radical gastrectomy. Pathologic TNM stage has been used as one of the best prognostic markers of gastric cancer, but there are still large variations even at the same stage. Therefore, it is crucial to find out the molecular biomarkers that can predict the different prognosis among patients with the same TNM staged cancer. Moreover, the identification of biomarkers followed by the development of biomarker-derived targeted therapies may improve the clinical outcome like trastuzumab for human epidermal growth factor receptor 2 (HER-2)-positive gastric cancers [2].

CD44, a major adhesion molecule for the extracellular matrix, is a cell surface receptor for hyaluronic acid [3], and implicated various biological processes, such as cell adhesion [4], cell migration [5], and cancer metastasis [6]. It has been accepted as one of the cancer stem cells markers [7]. The isoforms produced by alternative mRNA splicing are abundantly expressed in epithelial-type carcinomas, although the standard CD44 isoform (CD44s) is expressed predominantly in hematopoietic cells and normal epithelial cell subsets. Among them, CD44 variant 9 (CD44v9) is highly expressed at the proliferative and stem-like cells in mouse gastric tumors [8]. In addition, CD44v9 may contribute to cancer survival in the worse environment, like high reactive oxygen species-generated condition from chemotherapy and/or radiotherapy, by augmenting reduced glutathione though an activating cysteine-glutamate exchange transporter [9]. These findings suggested that CD44v9 might be a good target for the biomarker-driven cancer treatment. Therefore, we conduct this study to determine whether CD44v9 is selectively expressed in gastric cancer cells, and whether it serves as a prognostic marker of gastric cancer at the same stage.
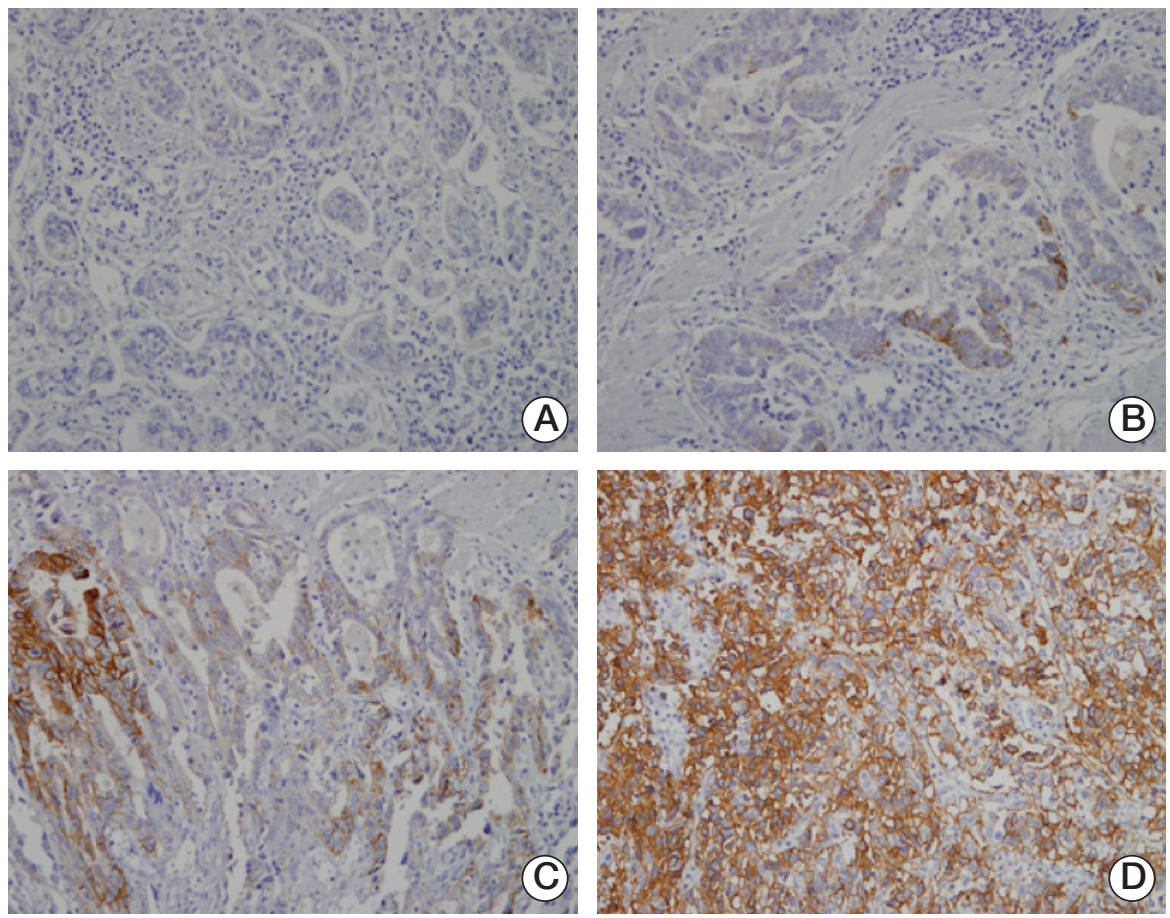

Fig. 1. Representative figures of immunohistochemical staining for CD44 variant 9 (CD44v9) expression on the basis of positive criteria. Membranous reactions were scored in accordance to the percentage of CD44v9-positive cells as follows: (A) immunonegativity $(0 \%-4 \%),(\mathrm{B}) 1+$ reactivity intensity $(5 \%-19 \%),(\mathrm{C}) 2+$ reactivity intensity $(20 \%-49 \%),(\mathrm{D}) 3+$ reactivity intensity $(50 \%-100 \%)(A-D, \times 200)$. 

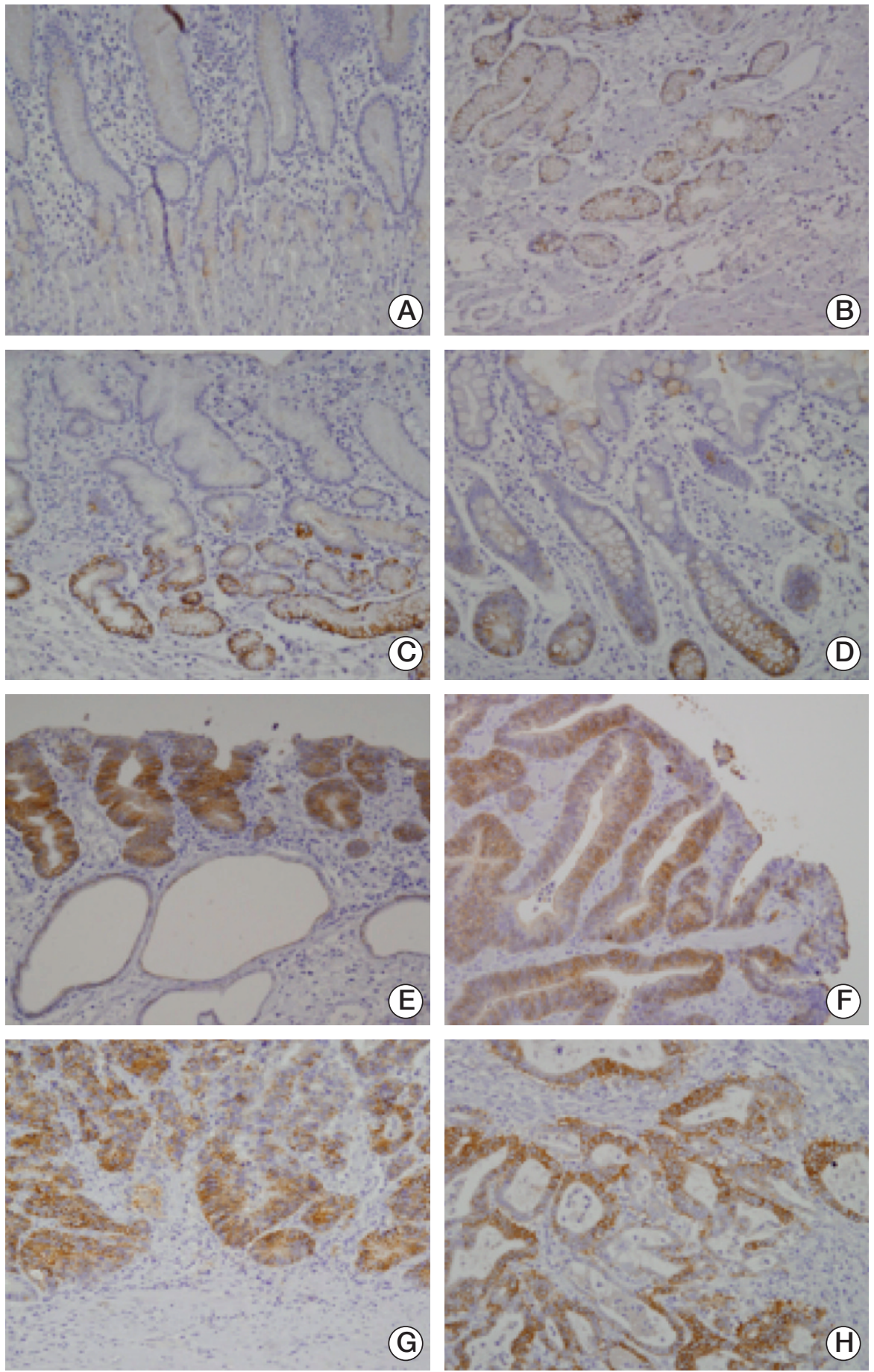

Fig. 2. Representative findings of immunohistochemical staining for CD44 variant 9 (CD44v9) in various gastric tissues. (A) Foveolar and fundic gland cells in normal tissue. Most of the foveolar and fundic gland cells were negative for CD44v9. (B) Antral gland cells in normal tissue. Some of the neck cells and antral gland cells were positive for CD44v9. (C) Antral gland cells in Helicobacter pylori-infected gastritis mucosa. Some of the antral gland cells in this H. pylori-infected gastric mucosa were positive for CD44v9. (D) Intestinal metaplastic cells. Some of the intestinal metaplastic cells were positive for CD44v9. (E) Low-grade tubular adenoma. (F) High-grade tubular adenoma. Many tumor cells are positive in a high-grade tubular adenoma. (G) Early gastric cancer cells. Many tumor cells were positive in an early gastric cancer confined within mucosa. (H) Advanced gastric cancer cells $(\mathrm{A}-\mathrm{H}, \times 200)$. 

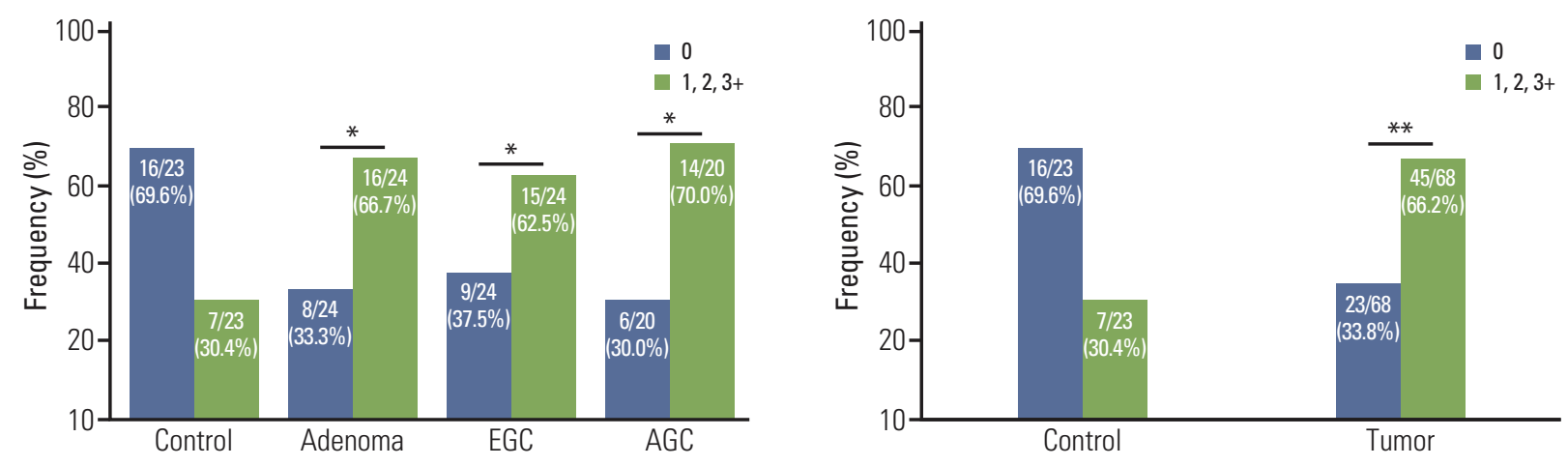

C
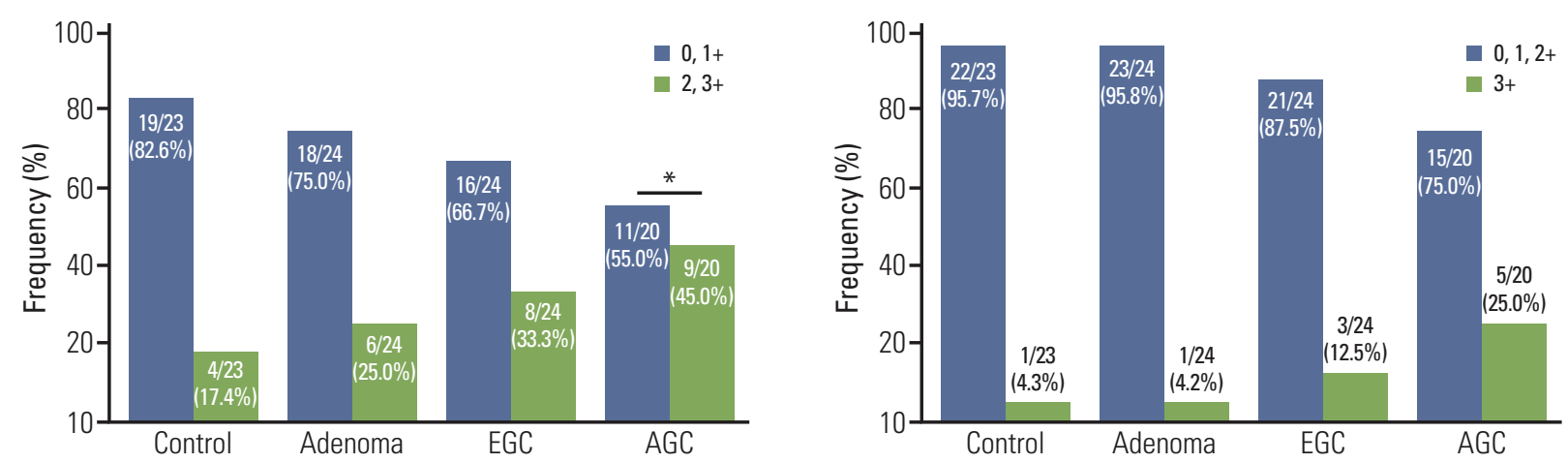

Fig. 3. CD44 variant 9 (CD44v9)-positive rates various gastric cancer tissues. Positive criteria for CD44v9 were defined as follows: immunohistochemical staining (IHC) score more than 0 (A, B), IHC score more than $1+(\mathrm{C})$, and $\mathrm{IHC}$ score of $3+(\mathrm{D})\left({ }^{*} \mathrm{p}<0.05\right.$ and ${ }^{* *} \mathrm{p}<0.01$, vs. control). EGC, early gastric cancer; AGC, advanced gastric cancer.

\section{Materials and Methods}

\section{Clinical specimens and patients}

We used two kinds of the tissue microarray samples; one is containing the tissue samples for the evaluation of carcinogenesis (5 normal tissue, 6 Helicobacter pylori associated gastritis, 12 intestinal metaplasia, 12 low-grade adenoma, 12 high-grade adenoma, 24 EGC and 20 advanced gastric cancer [AGC], and the other is containing 333 gastric cancer tissues derived from the patients who underwent gastrectomy for gastric cancer from 1999 to 2007). The non-tumor samples were obtained from the endoscopic submucosal dissection or polypectomy for the benign polyps. For the tissue microarray, we obtained 2-mm-diameter core tissue biopsies from individual formalin-fixed and paraffin-embedded tissues and arranged them in new recipient paraffin blocks. In the cases of gastric carcinoma tissues, we obtained one tissue core from the area near the invasive front. Institutional Review Board permission of Gyeongsang National University Hospital was obtained for the use of these samples for this analysis (GNUHIRB-2009-19).

\section{Immunohistochemical staining}

Immunohistochemical staining (IHC) was performed on a 4 - $\mu \mathrm{m}$-thick section. Briefly, the tissue section was deparaffinized and rehydrated. Slides were incubated in $3 \% \mathrm{H}_{2} \mathrm{O}_{2}$ for 10 minutes to reduce nonspecific background staining due to endogenous peroxidase. For epitope retrieval, specimens were heated for 20 minutes in $10 \mathrm{mmol} / \mathrm{L}$ citrate buffer ( $\mathrm{pH}$ 6.0) in a microwave oven $(700 \mathrm{~W})$. After the treatment of Ultra V Block (Lab Vision Co., Fremont, CA) for 7 minutes at room temperature to block background staining, slides were incubated with a monoclonal antibody specific to 
Table 1. Baseline characteristics of patients

\begin{tabular}{|c|c|c|c|}
\hline Characteristic & CD44v9 positive $(\mathrm{n}=164)$ & CD44v9 negative ( $\mathrm{n}=169)$ & p-value \\
\hline Median age (range, yr) & $66(26-85)$ & $63(24-81)$ & \\
\hline \multicolumn{4}{|l|}{ Sex } \\
\hline Male & $104(63.4)$ & $114(67.5)$ & \multirow{2}{*}{0.438} \\
\hline Female & $60(36.6)$ & $55(32.5)$ & \\
\hline \multicolumn{4}{|l|}{ Location } \\
\hline Upper & $21(11.8)$ & $21(12.4)$ & \multirow{3}{*}{0.987} \\
\hline Middle & $31(18.9)$ & $33(19.5)$ & \\
\hline Lower & $112(68.3)$ & $115(68.0)$ & \\
\hline \multicolumn{4}{|l|}{ Operation } \\
\hline Subtotal gastrectomy & $115(70.1)$ & $117(69.2)$ & \multirow[t]{4}{*}{0.921} \\
\hline Total gastrectomy & $41(25.0)$ & $41(24.3)$ & \\
\hline Proximal gastrectomy & $6(3.7)$ & $9(5.3)$ & \\
\hline Wedge resection & $2(1.2)$ & $2(1.2)$ & \\
\hline \multicolumn{4}{|l|}{ No. of LN dissections } \\
\hline$<15$ & $28(17.1)$ & $24(14.2)$ & \multirow[t]{2}{*}{0.470} \\
\hline$\geq 15$ & $136(82.9)$ & $145(85.8)$ & \\
\hline \multicolumn{4}{|l|}{ TNM stage } \\
\hline I & $93(56.7)$ & $92(54.4)$ & \multirow[t]{3}{*}{0.884} \\
\hline II & $32(19.5)$ & $33(19.5)$ & \\
\hline III & $39(23.8)$ & $44(26.0)$ & \\
\hline \multicolumn{4}{|l|}{ Tumor size $(\mathrm{cm})$} \\
\hline$<4$ & $85(50.3)$ & $68(41.5)$ & \multirow[t]{2}{*}{0.106} \\
\hline$\geq 4$ & $84(49.7)$ & $96(58.5)$ & \\
\hline \multicolumn{4}{|l|}{ WHO classification } \\
\hline Well differentiated & $41(25.0)$ & $28(16.6)$ & \multirow[t]{6}{*}{$<0.001$} \\
\hline Moderately differentiated & $62(37.8)$ & $44(26.0)$ & \\
\hline Poorly differentiated & $48(29.3)$ & $72(42.6)$ & \\
\hline Signet-ring cell carcinoma & $4(2.4)$ & $23(13.6)$ & \\
\hline Mucinous adenocarcinoma & $7(4.3)$ & $1(0.6)$ & \\
\hline Undifferentiated & $2(1.2)$ & $1(0.6)$ & \\
\hline \multicolumn{4}{|l|}{ Lauren classification } \\
\hline Intestinal & $134(81.7)$ & $108(63.9)$ & \multirow[t]{3}{*}{$<0.001$} \\
\hline Diffuse & $21(12.8)$ & $55(32.5)$ & \\
\hline Mixed & $9(5.5)$ & $6(3.6)$ & \\
\hline
\end{tabular}

Values are presented as number (\%) unless otherwise indicated. CD44v9, CD44 variant 9; LN, lymph node; WHO, World Health Organization.

CD44v9 (kindly provided by Dr. Hideyuki Saya, diluted 1:10,000 to $0.1 \mu \mathrm{g} / \mathrm{mL}$; Keio University School of Medicine, Tokyo, Japan), for 1 hour at room temperature. Primary antibody binding was detected by the UltraVision LP Detection System (Lab Vision Co.) in accordance to the manufacturer's recommendations. The color development was performed with 3-3'-diaminobenzidine and counterstained with hematoxylin. For CD44v9, the degree of the epitope expression was scored as 0 when less than $5 \%$ of tumor cells were stained, $1+$ when 5\%-19\% of tumor cells were stained, $2+$ when $20 \%-49 \%$ of tumor cells were stained, and $3+$ when
$50 \%$ or more of tumor cells were stained. IHC score of more than 0 was used as positive criteria in unspecified cases. Histological type was described using the World Health Organization (WHO) and Lauren classification, and tumor stage was classified in accordance to the American Joint Committee on Cancer TNM system.

\section{Statistical analysis}

Chi-square test was used to identify any correlations between the immunohistochemical expressions of CD44v9 


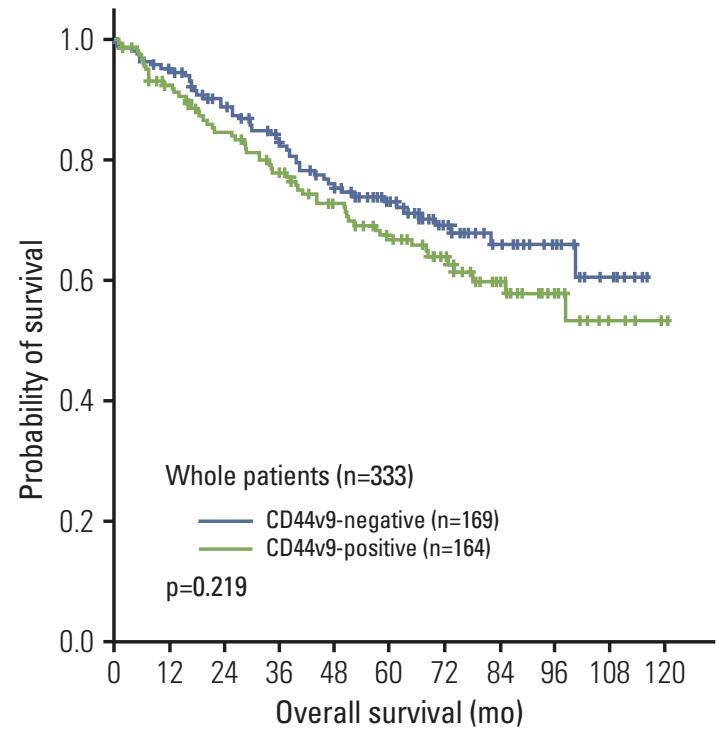

Fig. 4. Kaplan-Meier curves for overall survival according to CD44 variant 9 (CD44v9) status in the whole patients.

and clinical parameters, such as histological type, TNM stage, and location of cancer development.

Overall survival (OS) was defined as the time from operation to death of any cause or last follow-up. The survival curve was calculated by the Kaplan-Meier method and the difference was analyzed by a log-rank test between the positive and negative groups on the basis of CD44v9 expression. For the multivariate Cox regression models, all the variables with moderate survival association $(\mathrm{p}<0.10)$ were included. Internal validation with bootstrap (1,000 replications) was performed to validate the final model. A statistical analysis was performed using SPSS ver. 21.0 (SPSS Inc., Chicago, IL). A two-sided $\mathrm{p}<0.05$ was considered statistically significant.

Post-hoc power (1- $\beta)$ calculations were performed to determine whether the sample size was adequate to find a significant difference between the variables, using effect sizes derived from this study.

\section{Results}

\section{CD44v9-positve rate increased as the tissue became malignant}

To determine whether CD44v9 is selectively expressed in cancer cells, we assessed the expression of CD44v9 in normal gastric mucosa, $H$. pylori-infected gastric mucosa, low-grade adenoma, high-grade adenoma, EGC, and AGC. The representative figures of CD44v9 IHC are shown in Figs. 1 and 2. In normal gastric mucosa, mainly weak staining intensity and up to $1+$ immunoexpression for CD44v9 were found only on the basolateral membrane of the epithelial cells of the pyloric glands while foveolar epithelia and fundic glands were negative for $\mathrm{CD} 44 \mathrm{v} 9$ (Fig. 2A). CD44v9-positive rates by histologic types were depicted in Fig. 3 . The positive expression rates for $\mathrm{CD} 44 \mathrm{v} 9$ in tumor, including adenoma, EGC, and AGC $(66.2 \%, 45 / 68)$, were higher than those in normal and gastritis tissues $(30.4 \%, 7 / 23, \mathrm{p}=0.003$ ) (Fig. 3A and B). Post-hoc analysis of power revealed that this study had $86 \%$ power to detect a difference in the proportion of $35.8 \%$ between the control and tumor groups in 91 samples, with a two-sided $\alpha=0.05$. The degree of positive expression was increased as tissues become malignant (Fig. 3C and D).

\section{CD44v9-positive rates differ by WHO and Lauren clas- sification}

To investigate the clinical significance of CD44v9 in gastric cancer, we used the second tissue microarray that contains 333 gastric cancer patients. The expression patterns of CD44v9 are outlined by clinical variables (Table 1 ). The median age of patients was 66 years (range, 26 to 85 years) and 63 years (range, 24 to 81 years) in CD44v9-positive and CD44v9-negative group, respectively. The median follow-up duration was 77.7 months (range, 1.2 to 167.7 months) and 77.1 months (range 0.6 to 175.8 months) in CD44v9-positive and $\mathrm{CD} 44 \mathrm{v} 9$-negative group, respectively. There were no significant differences in the positive rates for CD44v9 in accordance to gender, location, operation, and tumor stages. However, the positive rates for $\mathrm{CD} 44 \mathrm{v} 9$ decreased in poorly differentiated adenocarcinoma and signet-ring cell carcinoma ( $\mathrm{p}<0.001)$, and were higher in the intestinal type than in the diffuse type $(\mathrm{p}<0.001)$.

\section{Immunoexpression of CD44v9 serves as a prognostic marker in EGC}

OS in the whole patients was not statistically different between the CD44v9-positive and CD44v9-negative groups, although the $\mathrm{CD} 44 \mathrm{v} 9$-positive group tended to show a worse survival outcome than the $\mathrm{CD} 44 \mathrm{v} 9$-negative group (5-years survival rate [5-YSR], $66.8 \%$ vs. $73.1 \%, \mathrm{p}=0.219)$, and the survival difference became bigger as time passed (Fig. 4). The subgroup analysis by TNM stage revealed that the CD44v9positive group carried worse survival outcome than the CD44v9-negative group did in the patients with stage I (5-YSR, $81.7 \%$ vs. 95.2\%, respectively; $\mathrm{p}=0.013$ ) (Fig. 5A), whereas there was no survival differences between the 

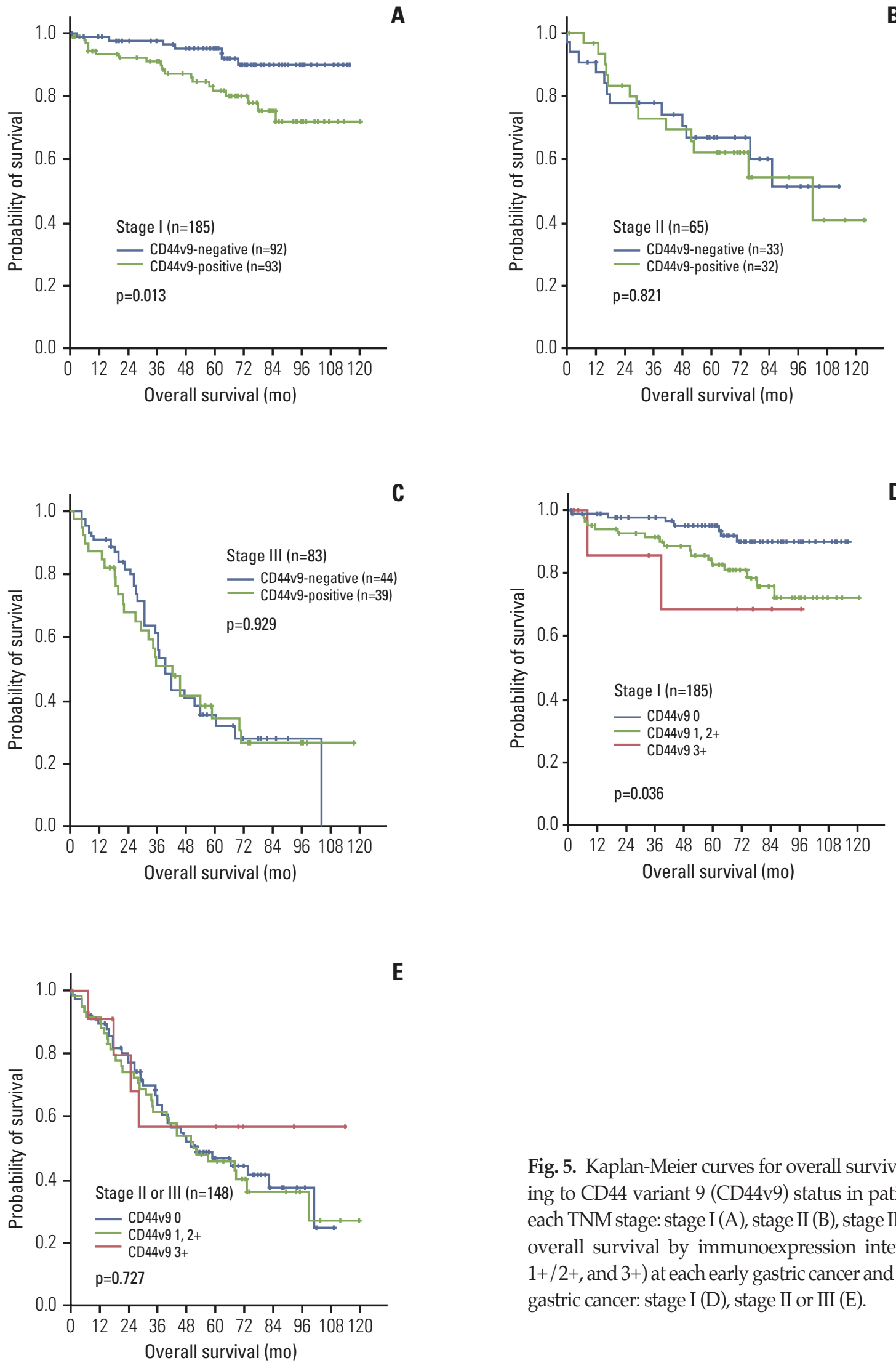

Fig. 5. Kaplan-Meier curves for overall survival according to $\mathrm{CD} 44$ variant $9(\mathrm{CD} 44 \mathrm{v} 9)$ status in patients with each TNM stage: stage I (A), stage II (B), stage III (C). The overall survival by immunoexpression intensities $(0$, $1+/ 2+$, and $3+$ ) at each early gastric cancer and advanced gastric cancer: stage I (D), stage II or III (E). 
CD44v9-positive and CD44v9-negative groups in stage II (5-YSR, $66.9 \%$ vs. $62.2 \%$, respectively; $\mathrm{p}=0.821$ ) or stage III (5-YSR, 34.5\% vs. 32.0\%, respectively; $p=0.929$ ) (Fig. 5B and $\mathrm{C})$. In a multivariate analysis, old age, male sex, and positive CD44v9 (hazard ratio, 3.375; 95\% confidence interval, 1.413 to $8.063 ; \mathrm{p}=0.006$ ) were independent poor prognostic factors for OS in patients with stage I disease (Table 2). This finding was internally validated from the 1,000 bootstrap samples (Table 2). A post-hoc analysis for power revealed that this study had $83 \%$ power to detect a hazard ratio of 3.375 between the CD44v9-positive and CD44v9-negative groups in 185 patients with stage I, with a two-sided $\alpha=0.05$ and an attrition rate of 0.001 per month.

Next, we also assessed the differences in OS dependent on the degree of the immunoexpression of CD44v9. The survival curve showed that patients with $3+$ immunoexpression of CD44v9 appeared to have worse survival rates than those with $1+$ or $2+$ immunoexpression in stage I, whereas it was statistically insignificant in stage II or III (Fig. 5D and E).

\section{Higher expression of CD44v9 may be served as criteria indicating a high risk for lymph node metastasis}

Here, we investigated a correlation between CD44v9positivity and lymph node metastasis. We applied the three different positive criteria for CD44v9 in accordance to tumor staining intensity, in order to determine whether CD44v9positive cancer has more chance to lymph node metastasis. As shown in Table 3, cancers with strong expression (3+) showed more prevalent lymph node metastases, whereas moderate $(2+)$ or weak $(1+)$ expression did not show similar trends of lymph node metastases.

Next, we determined whether CD44v9-positivity is maintained in the metastatic lymph node and whether CD44v9positivity becomes changed in the metastatic lymph node from CD44v9-negative primary tumor. Here, we used tissue block that contains 20 patient primary cancer tissues matched with the metastatic lymph node. As shown in Table 3, the concordance in positivity for CD44v9 between primary tumor and lymph node was bigger when we used higher expression of CD44v9 as the positive cutoff value.

\section{Discussion}

This study was designed to determine whether CD44v9 can be a target for biomarker-driven gastric cancer treatment. Hence, we investigated whether CD44v9 is selectively expressed in gastric cancer cells, and whether CD44v9 serves as a prognostic biomarker in the patients with the same TNM stage. Here, we assessed the CD44v9 expression profile from normal cells to cancer cells, and then investigated the prognostic capability of CD44v9 in gastric cancer at the same TNM stage.

First, we found that CD44v9 was more frequently expressed in tumorous tissues than non-tumorous tissues, suggesting that CD44v9 may be associated with gastric carcinogenesis, and can be a selective target for the gastric cancer chemoprevention or therapy. Then, we showed that positive immunoexpression of CD44v9 serves as a poor prognostic indicator in EGC (stage I cancer) whereas it did not serves as a prognostic biomarker in AGC (stage II or III cancer). In addition, the strong positive expression (3+) for CD44v9 appeared to be associated with poor prognosis only in EGC. This result was different from previous data, which suggested that CD44v9 was associated with lymph node metastasis, cancer invasion, and final TNM stages [10]. Moreover, CD44 isoforms has been implicated in distant metastasis as well as lymph node metastasis in patients with colon cancer [11]. However, they showed that the expression of CD44v9 became weaker or unchanged as cancer invasion became advanced and histology became poorly differentiated. These findings cannot be easily explained, because the expression of CD44 variant would theoretically be stronger in advanced cancer with poorly differentiated type if the CD44v9 plays an important role in advanced cancer. To support our data, we performed meta-analysis of the previous data. The summary estimate for the effects of the CD44 variant on survival from the previous data [12-14] showed that the positive expression of CD44 variants suggested poor prognosis (Fig. 6), and the hazard ratio of the positive expression of CD44v9 was highest in the EGC group. These results favor the finding that CD44v9 expression can be a useful prognostic biomarker especially for EGC. Although at this point it is premature to speculate on the reasons, our data suggest that CD44v9 may play an important role mainly in early carcinogenesis and early stage cancer progression because of the following reason; the positive expression rates for CD44v9 became lower as the cancer cell became poorly differentiated, and the positive expression rates were not increased between EGC (TNM stage I) and AGC (TNM stage II and III) (Table 1). Another reason is that previous data showed that the hazard ratio for death or recurrence was much greater in the study for EGC [12] than those in other studies with AGC (Fig. 6). The latter part is also supported by the previous data [10]. To validate this data, some more studies are required.

In this paper, we also demonstrated that a strong positive expression (3+) of CD44v9 appeared to be a more valid indicator for the evaluation of the effects of CD44v9 on the lymph node metastasis by showing the association of degree of CD44v9 expression with the presence of lymph node metas- 
Table 2. Cox proportional hazard model and validation from 1,000 bootstrap samples for overall survival in patients with stage I $(n=185)$

\begin{tabular}{|c|c|c|c|c|c|c|c|c|}
\hline \multirow[b]{2}{*}{ Variable } & \multicolumn{3}{|c|}{ Univariate } & \multicolumn{5}{|c|}{ Multivariate } \\
\hline & HR & $95 \% \mathrm{CI}$ & p-value & HR & $95 \% \mathrm{CI}$ & p-value & $\begin{array}{c}95 \% \text { CI } \\
\text { (bootstrap) }\end{array}$ & $\begin{array}{c}\text { p-value } \\
\text { (bootstrap) }\end{array}$ \\
\hline \multicolumn{9}{|l|}{ Age $(y r)^{a)}$} \\
\hline$<65$ & Reference & & & Reference & & & & \\
\hline$\geq 65$ & 2.453 & $1.066-5.646$ & 0.035 & 2.480 & $1.076-5.714$ & 0.033 & $0.137-1.981$ & 0.017 \\
\hline \multicolumn{9}{|l|}{ Sex ${ }^{a}$} \\
\hline Female & Reference & & & Reference & & & & \\
\hline Male & 3.688 & $1.107-12.284$ & 0.034 & 4.572 & $1.365-15.316$ & 0.014 & $0.525-12.839$ & 0.018 \\
\hline \multicolumn{9}{|l|}{ Location } \\
\hline Lower & Reference & & & - & & & & \\
\hline Upper or middle & 1.204 & $0.536-2.702$ & 0.653 & - & - & - & - & - \\
\hline \multicolumn{9}{|l|}{ Tumor size $\left.(\mathrm{cm})^{\mathrm{b}}\right)$} \\
\hline$\leq 2.7$ & Reference & & & - & & & & \\
\hline$>2.7$ & 0.891 & $0.412-1.927$ & 0.770 & - & - & - & - & - \\
\hline \multicolumn{9}{|l|}{ WHO classification } \\
\hline $\mathrm{W} / \mathrm{D}$ or $\mathrm{M} / \mathrm{D}$ & Reference & & & - & & & & \\
\hline Others ${ }^{c)}$ & 0.593 & $0.249-1.411$ & 0.237 & - & - & - & - & - \\
\hline \multicolumn{9}{|c|}{ Lauren classification } \\
\hline Intestinal & Reference & & & - & & & & \\
\hline Diffuse or mixed & 0.985 & $0.395-2.452$ & 0.973 & - & - & - & - & - \\
\hline \multicolumn{9}{|c|}{ No. of LN dissections } \\
\hline$\geq 15$ & Reference & & & - & & & & \\
\hline$<15$ & 1.752 & $0.760-4.039$ & 0.188 & - & - & - & - & - \\
\hline \multicolumn{9}{|l|}{ CD44v9a) } \\
\hline Negative & Reference & & & Reference & & & & \\
\hline Positive & 2.860 & $1.202-6.805$ & 0.017 & 3.375 & $1.413-8.063$ & 0.006 & $0.384-2.420$ & 0.004 \\
\hline
\end{tabular}

HR, hazard ratio; CI, confidence interval; WHO, World Health Organization; W/D, well differentiated; M/D, moderately differentiated; LN, lymph node; CD44v9, CD44 variant 9. ${ }^{\text {a) } V a r i a b l e s ~ u s e d ~ i n ~ m u l t i v a r i a t e ~ a n a l y s i s, ~}{ }^{\mathrm{b}}$ Median tumor size was $2.7 \mathrm{~cm}$ in stage I, c)Poorly differentiated adenocarcinoma, signet-ring cell carcinoma, and mucinous adenocarcinoma were included in this category.

Table 3. Impact of CD44v9 of primary tumor on lymph node metastasis

\begin{tabular}{|c|c|c|c|c|c|c|c|c|}
\hline \multirow{2}{*}{$\begin{array}{l}\text { Positive } \\
\text { criteria }\end{array}$} & \multirow{2}{*}{$\begin{array}{l}\text { CD44v9 } \\
\text { status }\end{array}$} & \multicolumn{2}{|c|}{$\begin{array}{l}\text { Lymph node } \\
\text { metastasis }\end{array}$} & \multirow[t]{2}{*}{$p$-value } & \multirow{2}{*}{$\begin{array}{l}\mathrm{CD} 44 \mathrm{v} 9 \text { status in } \\
\text { primary tumor }\end{array}$} & \multicolumn{2}{|c|}{$\begin{array}{l}\text { CD44v9 status in } \\
\text { lymph node }\end{array}$} & \multirow[t]{2}{*}{ p-valu } \\
\hline & & Presence & Absence & & & Positive & Negative & \\
\hline \multirow[t]{2}{*}{$\geq 1$} & Positive & $65(39.6)$ & $99(60.4)$ & \multirow[t]{2}{*}{0.659} & Positive & $8(72.7)$ & $3(27.3)$ & \multirow[t]{2}{*}{0.175} \\
\hline & Negative & $63(37.3)$ & $106(62.7)$ & & Negative & $3(33.3)$ & $6(66.7)$ & \\
\hline \multirow[t]{2}{*}{$\geq 2$} & Positive & $31(44.3)$ & $39(55.7)$ & \multirow[t]{2}{*}{0.258} & Positive & $5(62.5)$ & $3(37.5)$ & \multirow[t]{2}{*}{0.018} \\
\hline & Negative & $97(36.9)$ & $166(63.1)$ & & Negative & $1(8.3)$ & $11(91.7)$ & \\
\hline \multirow[t]{2}{*}{$\geq 3$} & Positive & $12(60.0)$ & $8(40.0)$ & \multirow[t]{2}{*}{0.041} & Positive & $4(100)$ & 0 & \multirow[t]{2}{*}{$<0.001$} \\
\hline & Negative & 116 (37.1) & $197(62.9)$ & & Negative & 0 & $16(100)$ & \\
\hline
\end{tabular}

Values are presented as number (\%). CD44v9, CD44 variant 9. 


\begin{tabular}{lrrrrr} 
Study name & \multicolumn{5}{c}{ Statistics for each study } \\
\cline { 2 - 6 } & $\begin{array}{c}\text { Hazard } \\
\text { ratio }\end{array}$ & $\begin{array}{c}\text { Lower } \\
\text { limit }\end{array}$ & $\begin{array}{c}\text { Upper } \\
\text { limit }\end{array}$ & z-value & p-value \\
& & & & & \\
Hirata et al. (2013)a) [12] & 19.770 & 9.078 & 42.750 & 7.540 & 0.000 \\
Yamamichi et al. (1998) [13] & 4.960 & 2.830 & 8.692 & 5.595 & 0.000 \\
Yamaguchi et al. (2002) [14] & 4.376 & 2.765 & 6.926 & 6.303 & 0.000 \\
& 7.139 & 3.195 & 15.948 & 4.793 & 0.000
\end{tabular}

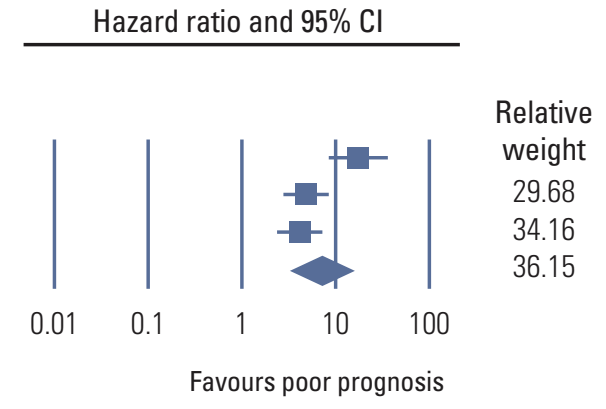

Fig. 6. The positive expression of CD44 variants and prognosis in a meta-analysis of the previous studies ( $\mathrm{n}=5)$. ${ }^{\text {a) }} \mathrm{Hirata}$ et al. [12] studied with early gastric cancer alone and the end point was recurrence. Diamonds are the summary estimate from the pooled studies with $95 \%$ confidence interval (CI).

\begin{tabular}{lcccc} 
Study name & \multicolumn{4}{c}{ Statistics for each study } \\
\cline { 2 - 5 } & $\begin{array}{l}\text { Odds } \\
\text { ratio }\end{array}$ & $\begin{array}{c}\text { Lower } \\
\text { limit }\end{array}$ & $\begin{array}{c}\text { Upper } \\
\text { limit }\end{array}$ & p-value \\
& & & & \\
Yasui et al. (1998) [10] & 4.615 & 1.944 & 10.955 & 0.001 \\
Yamaguchi et al. (1996) [11] & 1.343 & 0.671 & 2.689 & 0.405 \\
Kim et al. (1997) [16] & 0.867 & 0.129 & 5.817 & 0.883 \\
Muller et al. (1997) [17] & 0.978 & 0.619 & 1.546 & 0.924 \\
Muller et al. (1997) [17] & 1.494 & 0.997 & 2.240 & 0.052 \\
& 1.524 & 0.948 & 2.449 & 0.082
\end{tabular}

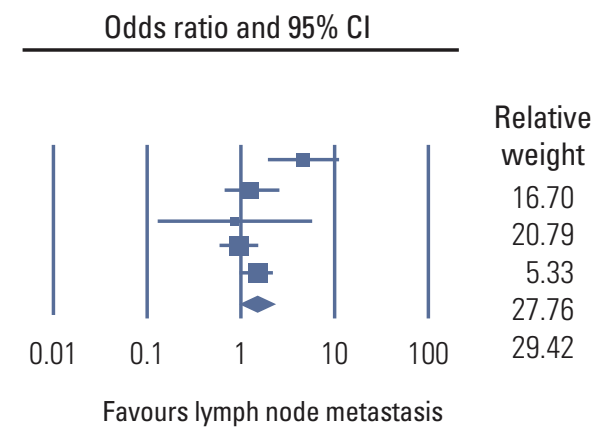

Fig. 7. The positive expression of CD44 variants and the risk of lymph node metastasis in a meta-analysis of the previous studies $(\mathrm{n}=5) .{ }^{\mathrm{a})} \mathrm{CD} 44 \mathrm{v5}$ : Muller et al. [17] studied both CD44v5 and CD44v6 in the same paper. The values were different, so we analyzed the data separately. Diamonds are the summary estimate from the pooled studies with $95 \%$ confidence interval (CI).

tasis and the concordance in the positivity of cancer cells between the primary cancer and the metastatic lymph node in the same patients. This finding is consistent with the previous results [10]. Although we found that an association between the $3+$ immunoexpression of CD44v9 and lymph node metastasis, the summary estimate of the effects on lymph node metastasis from the previous data [10,15-17] showed that there are controversies regarding the association between the positive expression of CD44 variants and lymph node metastasis (Fig. 7). tumorous tissues than non-tumorous tissues, and the positive immunoexpression of CD44v9 serves as a poor prognostic indicator in EGC (stage I cancer), but not in AGC (stage II or III cancer). These results suggest that CD44v9 expression can be a good biomarker for the prognosis of EGC, and may serve as a target protein for the treatment of EGC or chemoprevention. All of these findings need to be validated in a further study.

\section{Conflicts of Interest}

Conflict of interest relevant to this article was not reported.

In summary, CD44v9 was more frequently expressed in 


\section{Acknowledgments}

This study was supported by a grant of the National R\&D

Program for Cancer Control, Ministry for Health, Welfare and Family Affairs, Republic of Korea (0820050).

\section{References}

1. Jung KW, Won YJ, Kong HJ, Oh CM, Lee DH, Lee JS. Cancer statistics in Korea: incidence, mortality, survival, and prevalence in 2011. Cancer Res Treat. 2014;46:109-23.

2. Bang YJ, Van Cutsem E, Feyereislova A, Chung HC, Shen L, Sawaki A, et al. Trastuzumab in combination with chemotherapy versus chemotherapy alone for treatment of HER2-positive advanced gastric or gastro-oesophageal junction cancer (ToGA): a phase 3, open-label, randomised controlled trial. Lancet. 2010;376:687-97.

3. Aruffo A, Stamenkovic I, Melnick M, Underhill CB, Seed B. CD44 is the principal cell surface receptor for hyaluronate. Cell. 1990;61:1303-13.

4. Culty M, Miyake K, Kincade PW, Sikorski E, Butcher EC, Underhill $\mathrm{C}$. The hyaluronate receptor is a member of the CD44 (H-CAM) family of cell surface glycoproteins. J Cell Biol. 1990;111(6 Pt 1):2765-74.

5. Thomas L, Byers HR, Vink J, Stamenkovic I. CD44H regulates tumor cell migration on hyaluronate-coated substrate. J Cell Biol. 1992;118:971-7.

6. Gunthert U, Hofmann M, Rudy W, Reber S, Zoller M, Haussmann I, et al. A new variant of glycoprotein CD44 confers metastatic potential to rat carcinoma cells. Cell. 1991;65:13-24.

7. Dalerba P, Dylla SJ, Park IK, Liu R, Wang X, Cho RW, et al. Phenotypic characterization of human colorectal cancer stem cells. Proc Natl Acad Sci U S A. 2007;104:10158-63.

8. Ishimoto T, Oshima H, Oshima M, Kai K, Torii R, Masuko T, et al. CD44+ slow-cycling tumor cell expansion is triggered by cooperative actions of Wnt and prostaglandin E2 in gastric tumorigenesis. Cancer Sci. 2010;101:673-8.

9. Ishimoto T, Nagano O, Yae T, Tamada M, Motohara T, Oshima $\mathrm{H}$, et al. CD44 variant regulates redox status in cancer cells by stabilizing the $\mathrm{xCT}$ subunit of system $\mathrm{xc}(-)$ and thereby promotes tumor growth. Cancer Cell. 2011;19:387-400.

10. Yasui W, Kudo Y, Naka K, Fujimoto J, Ue T, Yokozaki H, et al. Expression of CD44 containing variant exon 9 (CD44v9) in gastric adenomas and adenocarcinomas: relation to the proliferation and progression. Int J Oncol. 1998;12:1253-8.

11. Yamaguchi A, Urano T, Goi T, Saito M, Takeuchi K, Hirose K, et al. Expression of a CD44 variant containing exons 8 to 10 is a useful independent factor for the prediction of prognosis in colorectal cancer patients. J Clin Oncol. 1996;14:1122-7.

12. Hirata $K$, Suzuki $H$, Imaeda $H$, Matsuzaki J, Tsugawa $H$, Nagano $\mathrm{O}$, et al. CD44 variant 9 expression in primary early gastric cancer as a predictive marker for recurrence. Br J Cancer. 2013;109:379-86.

13. Yamamichi K, Uehara Y, Kitamura N, Nakane Y, Hioki K. Increased expression of CD44v6 mRNA significantly correlates with distant metastasis and poor prognosis in gastric cancer. Int J Cancer. 1998;79:256-62.

14. Yamaguchi A, Goi T, Yu J, Hirono Y, Ishida M, Iida A, et al. Expression of CD44v6 in advanced gastric cancer and its relationship to hematogenous metastasis and long-term prognosis. J Surg Oncol. 2002;79:230-5.

15. Mulder JW, Kruyt PM, Sewnath M, Oosting J, Seldenrijk CA, Weidema WF, et al. Colorectal cancer prognosis and expression of exon-v6-containing CD44 proteins. Lancet. 1994;344: 1470-2.

16. Kim YS, Chi SG, Kim YW, Park YK, Yoon C. Molecular genetic characterization of alternatively spliced CD44 transcripts in human stomach carcinoma. J Korean Med Sci. 1997;12:505-13.

17. Muller W, Schneiders A, Heider KH, Meier S, Hommel G, Gabbert HE. Expression and prognostic value of the CD44 splicing variants v5 and v6 in gastric cancer. J Pathol. 1997; 183:222-7. 